\title{
Material investigations to facilitate the applicability of microwave radar to energy-related wall structure analysis
}

\author{
Philip Gorzalka (D) Alexander Haas - Galina Golubeva • Jacob Estevam Schmiedt (D) \\ Markus Peichl $10 \cdot$ Bernhard Hoffschmidt
}

Received: 5 February 2021 / Accepted: 2 May 2021/Published online: 26 May 2021

(C) The Author(s) 2021

\begin{abstract}
Existing buildings often have low energy efficiency standards. For the preparation of retrofits, reliable high-quality data about built-in materials is required. Contactless measuring technologies, especially microwave radar, have the potential to enable an easy-to-apply and automatable way to analyse the structures and thermal properties of existing building walls, but the relationship between materials, their thermal properties, and their electromagnetic properties, such as the permittivity, is needed for its application. This article presents an analysis of the relationship between electromagnetic and thermal properties for a variety of building materials. Systematic measurements were performed for samples (burnt clay bricks, calcium silicate bricks, autoclaved aerated concrete and lightweight concrete) mainly originating from demolished buildings. The thermal conductivity, thermal capacitance, and dielectric permittivity were
\end{abstract}

P. Gorzalka $(\bowtie) \cdot$ G. Golubeva

German Aerospace Center (DLR), Institute of Solar

Research, Karl-Heinz-Beckurts-Str. 13, 52428 Jülich, Germany

e-mail: Philip.Gorzalka@dlr.de

A. Haas - M. Peichl

German Aerospace Center (DLR), Microwaves and Radar Institute, Münchener Str. 20, 82234 Weßling, Germany

J. Estevam Schmiedt · B. Hoffschmidt

German Aerospace Center (DLR), Institute for the

Protection of Terrestrial Infrastructures, Rathausallee 12, 53757 Sankt Augustin, Germany measured and the hypothesis of a correlation between permittivity and thermal parameters was partly confirmed. This information is a prerequisite for using microwave radar sensing technology to determine heat transfer coefficients of existing building walls. The next research step is the development of a corresponding measurement and evaluation method.

Keywords Microwave radar · Heat transfer . Building material $\cdot$ Permittivity $\cdot$ Thermal conductivity

\section{Introduction}

Reducing heat demand in buildings is a key factor to cut down carbon emissions. Consequently, where the rate of buildings being newly built is low and heating is an important contributor to primary energy consumption, refurbishing existing buildings is a crucial measure [1]. Finding appropriate refurbishment solutions for an individual building benefits from an objective and accurate analysis of the status quo, including the composition and thermal parameters of the walls. However, non-destructive measurement methods to assess the U-values of existing walls require thermal gradients between inside and outside and the application of the measurement devices for 
several days $[2,3]$, resulting in significant costs and effort on execution.

Microwave radiation has the ability to penetrate deep into building walls. Using suitable radar technology, it is possible to determine the number of layers of unknown wall structures with sufficient accuracy [4]. When an electromagnetic wave hits a solid-state body, a process called polarisation occurs within the body volume where the stationary charge carriers are shifted in such a way that dipole moments are generated and aligned along the external electric field [5]. The relative permittivity $\varepsilon_{r}$, a material property, indicates how well a solid-state body can be polarised. The polarisation in the solid-state body is timedelayed to the external field, so the relative permittivity consists of a real and an imaginary part. In addition to the frequency and the speed of light, the real and imaginary parts have a decisive influence on the propagation constant $\gamma$ and thus on the attenuation behaviour of the electromagnetic wave in the medium [6]. If an electromagnetic wave hits the transition of two different materials, it is partially reflected, which can be made visible in radar images [7]. Determining the permittivities on the basis of these reflection measurements represents an inverse problem. In order to apply this method more robust, the use of several adjacent range profiles and the use of synthetic aperture radar techniques for improved structural information is useful. This also allows to limit the required search space for the number of layers, the layer thicknesses and the layer permittivities. The results of the first image analysis can then be used as a-priori information for the determination of the material parameters, which in turn can be used for an improved representation in the radar images [4].

The prerequisite for using this method for energetically oriented analyses of walls is to know the relationship between layer permittivities and building materials or - even better - thermal conductivities. There are some sources for building material permittivities in the literature [8], but they are usually given for a whole material type. As building materials show a significant range of thermal properties for a single type of stones [9], a study of the correlation between permittivity and thermal behaviour within material types is required. Johnson [10] found a correlation between electrical and thermal conductivity for bricks as early as 1938, which Powell [11] proposed as base for thermal conductivity measurement of dry samples.
Perinelli et al. [12] present an apparatus for electrical measurement of permittivity and, thereby, thermal conductivity, but they include only four material samples over a very wide range of thermal conductivity and permittivity.

In this paper, we present a study of the permittivity, thermal conductivity, specific heat and density for different types of bricks and lightweight concrete. Based on the results, we propose an approach to analyse wall layers and their thermal properties using microwave radar.

\section{Theory}

Both electromagnetic transfer and thermal conductivity are influenced by micro-scale mechanisms. This section contains an overview of the considered materials and their microstructure as well as of its influence on permittivity and thermal conductivity.

\subsection{Considered materials and their microstructure}

The material types considered in this paper are briefly described in the following.

- Burnt clay bricks (BCB) are made of clay, loam, sand and occasionally additional ingredients, meaning they mainly consist of aluminium silicates and silicon oxide. They are sintered at about $1000{ }^{\circ} \mathrm{C}$, which results in a crystalline structure with small grain sizes. Porosity and, therefore, density depend on the conditions of the manufacturing process. Red bricks get their colour from a higher ratio of ferric oxide, while yellow ones have more calcium oxide. However, the concentration of both compounds is low and the colour also depends on the conditions of the sintering process $[13,14]$.

- Calcium silicate bricks (CSB, also called sandlime bricks) are produced by hardening a mixture of burnt lime, sand and water at about $200{ }^{\circ} \mathrm{C}$. The finished bricks consist of sand that is bound by calcium silicate hydrates (C-S-Hs), a mixture of calcium oxide, silicon oxide and water [15].

- Autoclaved aerated concrete (AAC) is a light and comparatively new material and is, similar to calcium silicate bricks, made of burnt lime (and/or cement), fine sand and water. Before being 
hardened at about $200{ }^{\circ} \mathrm{C}$, it is foamed using aluminium powder. The sand dissolves into C-SHs at production $[14,15]$.

- Lightweight (aggregated) concrete (LAC, with open or closed structure) is produced out of a light aggregate (e.g. (volcanic) pumice or blast furnace slag) bound by cement and water into a porous brick. As a result, the finished material consists of the aggregate and binding C-S-Hs [16, 17].

We conclude that all materials have a structure of small crystalline grains, partly also on a macroscopic scale. Some of them contain water (in C-S-Hs) and metal (in blast furnace slag). However, the macroscopic structure is unordered and - like chemical composition and density - depends on the (regionally different) ingredients and on the individual manufacturing process. Furthermore, all materials are at least nearly nonconducting solids (dielectrics). Electrons cannot move freely within the crystals, with the exception of potential metallic residuals in aggregates (e.g. blast furnace slag). Finally, all material particles are very small compared to the wavelengths used for measurements. Hence they can be treated as homogeneous.

\subsection{Permittivity}

Permittivity measures the polarisability of a material in response to electric fields. Induced and permanent dipole moments arrange along these fields. As a consequence, materials in which dipoles can move, as for example liquid water, have high permittivities. As polarisation mechanisms differ in terms of their velocity of reorientation, permittivity is generally frequency-dependent [18]. The absolute permittivity $\varepsilon$ is the product of the vacuum permittivity $\varepsilon_{0}$ (a constant) and the relative permittivity $\varepsilon_{r}$ (a complexvalued material property). In the following, the expression permittivity relates only to the real part $\varepsilon_{r}^{\prime}$.

The Clausius-Mossotti equation

$\frac{\varepsilon_{r}-1}{\varepsilon_{r}+2}=\frac{N_{A} \cdot \rho \cdot \alpha}{3 \cdot M_{m} \cdot \varepsilon_{0}}$

allows for calculating the permittivity from other material parameters. Besides the Avogadro constant $N_{A}$, its application requires the knowledge of density $\rho$, molar mass $M_{m}$, and polarisability $\alpha$. The equation is only valid if "individual field effects of the surrounding molecules on the particle [...] mutually cancel", which is "reasonable [...] when the elementary particles are neutral and without permanent dipole moment, or when they are arranged either in complete disorder or in cubic or similar highly symmetrical arrays" [19]. As the symmetrical arrays (crystals) are small in our case, it is hard to say if the equation applies. Furthermore, values for polarisability are hardly available and grain borders and pores influence macroscopic permittivity. Nevertheless, for similarly composed materials with therefore similar molar mass and polarisability, equation (1) indicates that mainly the density determines the permittivity.

\subsection{Thermal conductivity}

In the of dielectrics, thermal energy (that is, vibration of molecules) is transferred through the crystals as vibrations of the lattice (phonons). For non-conducting solids, the thermal conductivity $k$ can be calculated as

$k=\frac{1}{3} \cdot(c \cdot v \cdot \Lambda)_{l}$

from the specific heat $c_{l}$, the average velocity $v_{l}$ and the mean free path $\Lambda_{l}$ of the lattice vibration. $c_{l}$ is related to the number density of oscillators $\eta=$ $N_{A} \cdot \rho / M_{m}$ through both Dulong-Petit law and $\mathrm{T}^{3}$ law. Additionally, the Cahill-Pohl model directly connects thermal conductivity to $\eta$ [20]. Neither of these equations allows linking to polarisability or permittivity, but the connection to density stands out. Moreover, air-filled pores will decrease both density and thermal conductivity.

All in all, both permittivity and thermal conductivity are based on different microscopic properties, but are correlated to the macroscopic density within closely related materials. Our main hypothesis is that there also might be a correlation between permittivity and thermal conductivity. In the presented experiments, we test this hypothesis and investigate whether it is possible to determine the thermal properties of building materials from radar measurements.

\section{Experimental methods}

This section describes how building material samples were collected, prepared and measured in the context of this work. 


\subsection{Material sources}

The samples were randomly collected at demolition sites. As a matter of circumstances, the majority originate from southwestern North Rhine-Westphalia, Germany. One BCB sample was found at Stockport, England.

\subsection{Sample preparation}

Generally, one sample per material type and construction site was prepared for measurement. Exceptions were made in cases of obvious variety within the same material type. In order to fit a microwave waveguide (a hollow metallic conductor, see 3.4) as part of a standard setup for permittivity measurements, and to provide smooth and even surfaces for thermal property measurement, each sample stone was shaped into two cuboids $(10.9 \times 5.46 \times 10 \mathrm{~cm}$ and $10.9 \times 5.46 \times 5 \mathrm{~cm})$ using a wet-cut masonry saw and grinding tools. To remove the water accumulated in that process, they were oven-dried at $210{ }^{\circ} \mathrm{C}$ for 26 hours. It was made sure that no additional loss of mass occurred within the last two hours. To reach a realistic dryness, the samples were afterwards stored under indoor (office) conditions until their mass remained constant.

\subsection{Thermal property measurement}

The thermal properties of the samples were measured using the transient plane source (TPS) technique, which has been shown to be accurate to within $\pm 5 \%$ for the thermal conductivity of building materials before [21]. A "Hot Disk" device and Kapton sensors of different size were applied.

\subsection{Permittivity measurement}

The permittivities of the samples investigated in this work were obtained using a waveguide as pictured in Fig. 1. With the help of a vector network analyser (VNWA) the four scattering parameters (transmission and reflection coefficients) of the samples were determined in the range between 1.7 and $2.6 \mathrm{GHz}$ for 1601 frequency steps. With the scattering parameters given, the real and imaginary parts of the stone samples' permittivities were computed with the Nicolson-Ross-Weir (NRW) method, which requires the knowledge of the length of the sample [22]. The

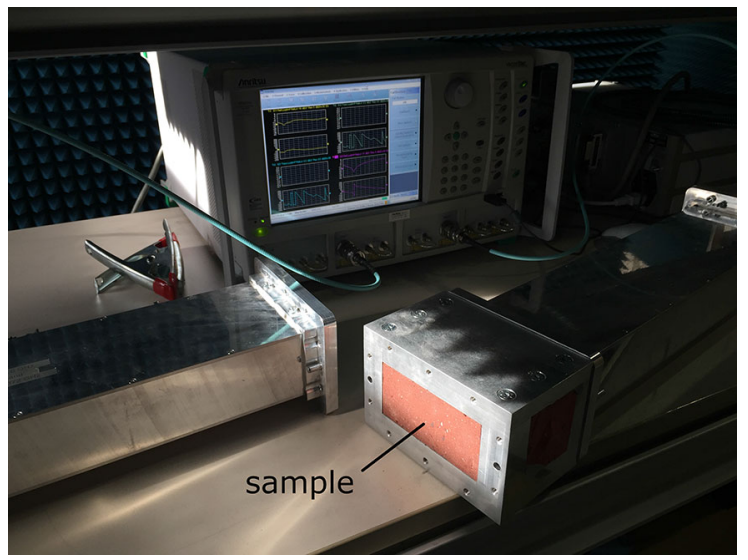

Fig. 1 Burnt clay brick sample in the waveguide in front of the vector network analyser

relative permeability was set to 1 in order to reach a better accuracy for the permittivity. The variation of permittivity values for the various frequency points does not exceed $1 \%$ compared to the overall average. In contrast to fluids, solids show a negligible frequency dependence in their permittivity behaviour. Therefore, the calculated values in the range of 1.7 and $2.6 \mathrm{GHz}$ can be used as a good approximation for a total relevant frequency range up to $20 \mathrm{GHz}$ for $\mathrm{BCB}$ and CSB. Only concrete shows a non-negligible frequency dependence in permittivity due to the high water content in the material mixture [23].

\subsection{Density measurement}

Sample densities were calculated as mass divided by net volume (including pores). Due to deviations from perfect cuboid shape, the volume values were doublechecked by determining the weight loss in water.

\section{Results and discussion}

The experiments gave material properties for 56 samples. 40 of them were burnt clay bricks of different type and colour, including four (partly) scorched ones. Additionally, seven CSB, two AAC and seven LAC (five with open and two with closed structure) samples were measured. Only a few samples had to be excluded because they did not fill the waveguide due to damages. 
Table 3 in the Appendix contains the average measured values for the properties of each sample. In this section, the results are presented and discussed. The imaginary part of the measured permittivities $\varepsilon_{r}^{\prime \prime}$ showed to be small, with the exception of a nonsignificant tendency to higher values for calcium silicate bricks. As the imaginary part of the complex permittivity was not considered for the expected correlation between density/heat transfer and permittivity, the following analysis focuses exclusively on the real part.

\subsection{Measured material property values and interrelations}

Figure 2 shows an overview of measured values for thermal conductivity (Fig. 2a) and specific heat (Fig. 2b) over permittivity for each investigated sample, with a visible positive correlation in both cases. For thermal conductivity and permittivity, the different materials are clearly grouped: Measurements for all BCB types form a highly correlated group. LAC with open structure and AAC values are grouped at lower values for both permittivity and thermal conductivity. LAC with closed structure and CSB samples cluster at lower and higher thermal conductivity values than the BCB group respectively. The overall correlation coefficient is 0.703 . Regarding specific heat and permittivity, all material types are included in the slightly asymptotic-looking interrelation with a correlation coefficient of 0.849 .

For analysing the contributions of the theoretically relevant quantities (as presented in Sect. 2) to these already high correlations, the different plots in Fig. 3 visualise our measurement results in greater detail. Furthermore, they allow us to observe from which measured quantities the variations originate. The plots are discussed in the following. As a complement, relevant correlation values are summarised in Table 1.

\subsubsection{Permittivity to density}

While Fig. 3a again shows a slightly asymptoticlooking interrelation between permittivity and density, it becomes almost linear when replacing permittivity by the left side of the Clausius-Mossotti equation (equation (1)). As a consequence, the correlation coefficient rises from 0.874 to 0.930 . The LAC with closed structure samples show strikingly off-correlation values, presumably because metallic contents of blast furnace slag aggregates increase their permittivity compared to other similarly dense materials.

\subsubsection{Density to thermal parameters}

When looking at thermal conductivity and density (Fig. 3c), the samples of different stone types are clearly grouped and show high internal consistence between the material properties, which is confirmed by

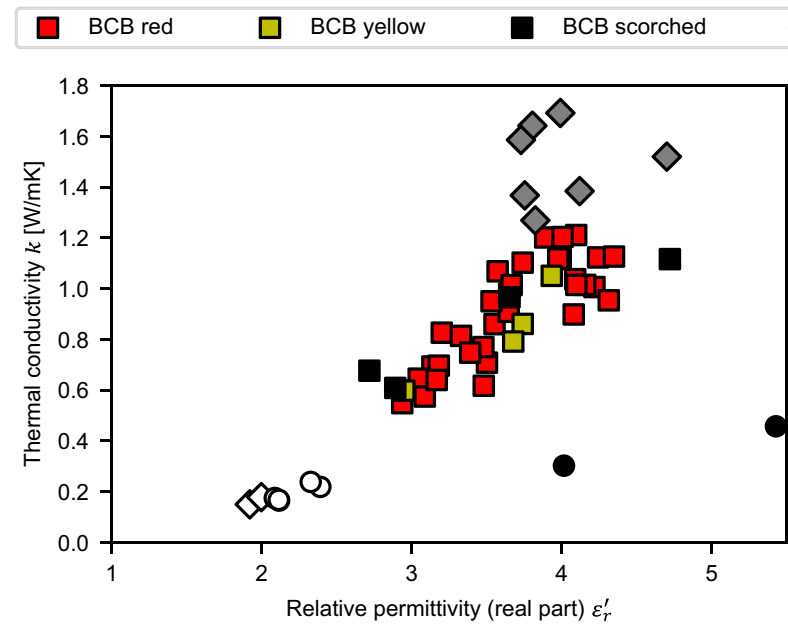

(a) Thermal conductivity over relative permittivity.

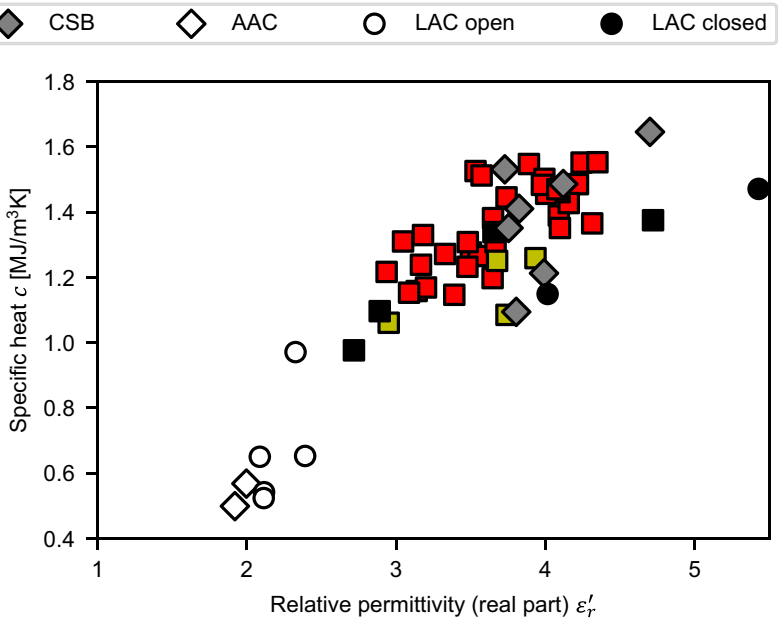

(b) Specific heat over relative permittivity.

Fig. 2 Overview of the relationships of thermal properties to permittivity for each individual investigated sample 


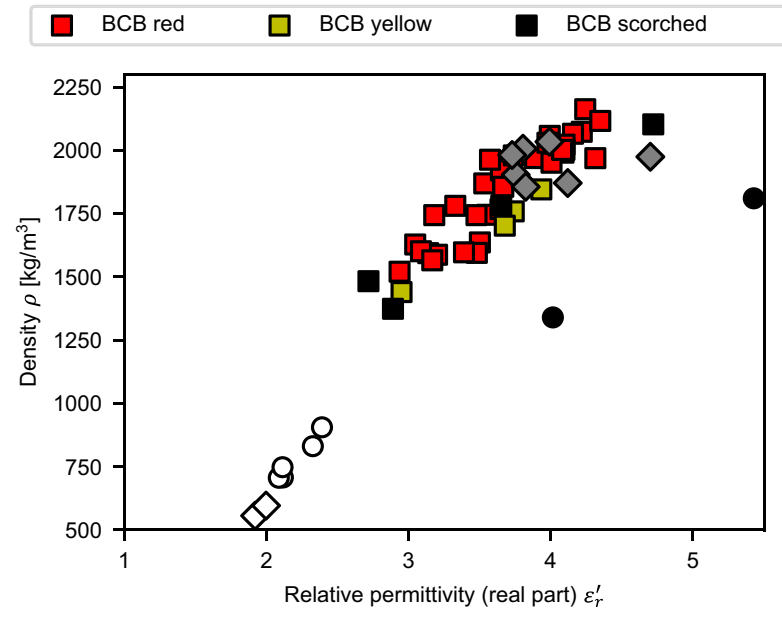

(a) Density over permittivity

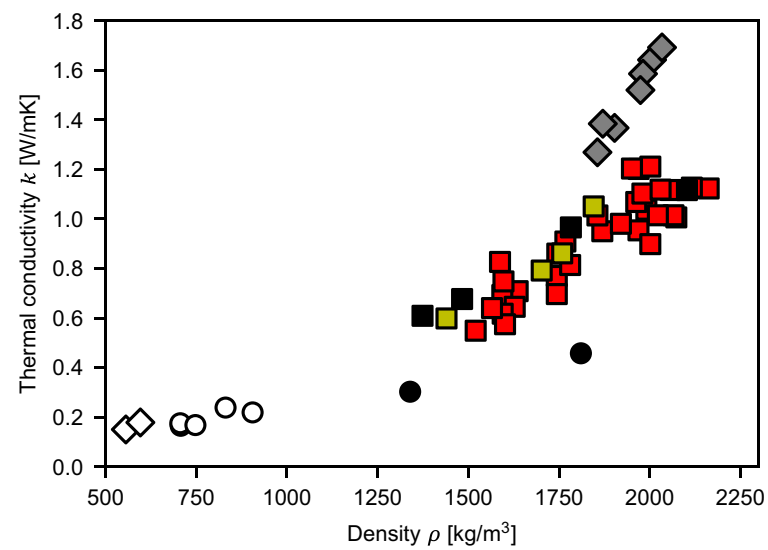

(c) Thermal conductivity over density

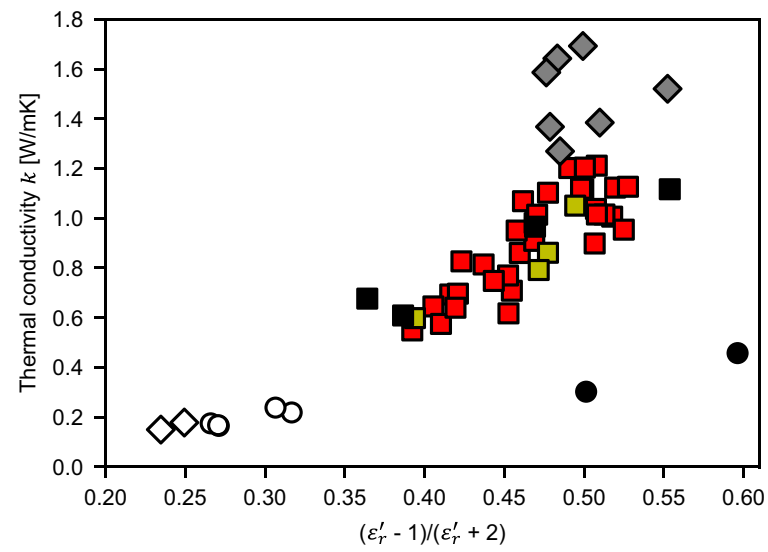

(e) Th. conductivity over left side of Clausius-Mossotti eq.

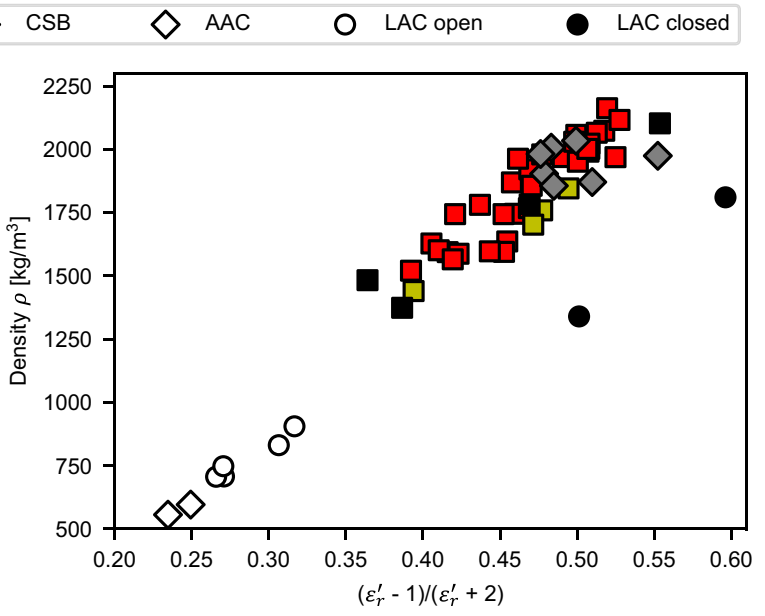

(b) Density over left side of Clausius-Mossotti equation

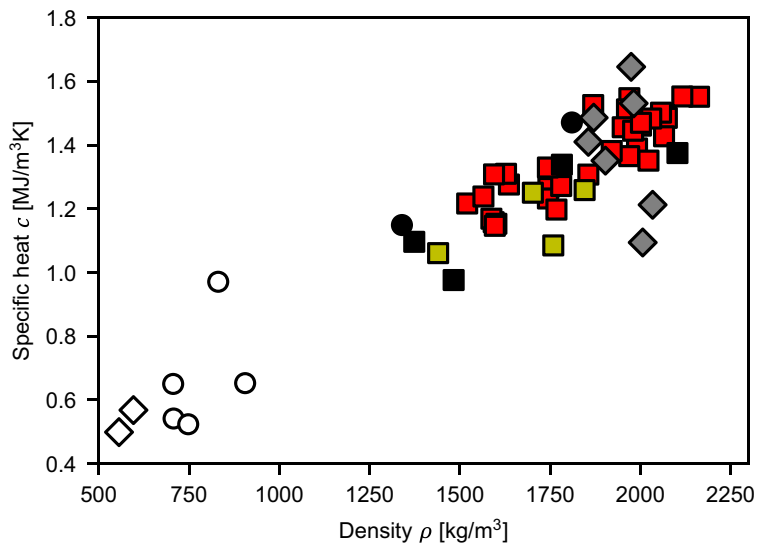

(d) Specific heat over density

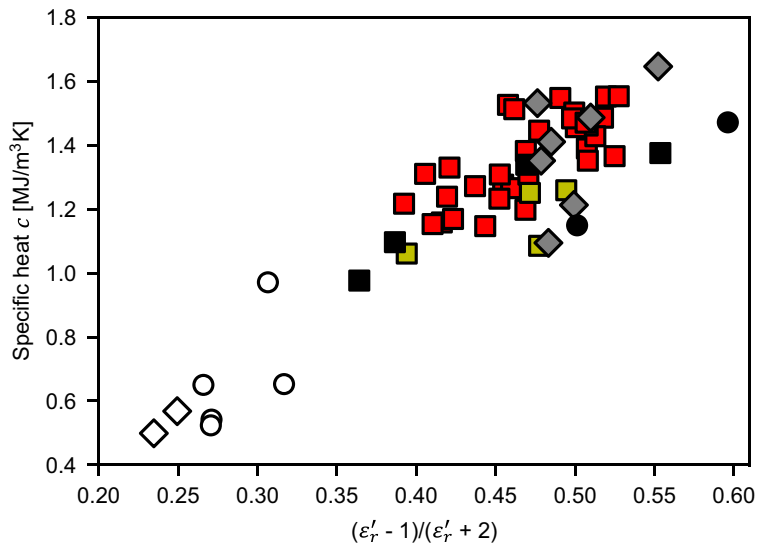

(f) Specific heat over left side of Clausius-Mossotti eq.

Fig. 3 Detailed visualisation of the relationships between thermal properties, density and permittivity for each individual investigated sample 
Table 1 Relevant correlation values between material properties from the sample measurements for all stones and within samples of similar material

\begin{tabular}{lllll}
\hline Parameters & All & BCB & CSB & LAC+AAC \\
\hline$\varepsilon_{r}^{\prime} \leftrightarrow \rho$ & 0.874 & 0.914 & 0.105 & 0.989 \\
$\mathrm{CM}\left(\varepsilon_{r}^{\prime}\right) \leftrightarrow \rho$ & 0.929 & 0.917 & 0.099 & 0.992 \\
$\rho \leftrightarrow k$ & 0.853 & 0.898 & 0.977 & 0.979 \\
$\rho \leftrightarrow c$ & 0.924 & 0.861 & -0.361 & 0.942 \\
$\mathrm{CM}\left(\varepsilon_{r}^{\prime}\right) \leftrightarrow k$ & 0.749 & 0.842 & 0.063 & 0.965 \\
$\varepsilon_{r}^{\prime} \leftrightarrow k$ & 0.703 & 0.833 & 0.063 & 0.976 \\
$\mathrm{CM}\left(\varepsilon_{r}^{\prime}\right) \leftrightarrow c$ & 0.895 & 0.734 & 0.544 & 0.947 \\
$\varepsilon_{r}^{\prime} \leftrightarrow c$ & 0.849 & 0.718 & 0.557 & 0.938 \\
\hline
\end{tabular}

$\mathrm{CM}\left(\varepsilon_{r}^{\prime}\right)$ stands for the left side of Clausius-Mossotti equation applied to the real part of the relative permittivity $\left(\varepsilon_{r}^{\prime}-1\right) /\left(\varepsilon_{r}^{\prime}+2\right)$

the correlation values in Table 1. Specific heat and density are shown as highly correlated in total by Fig. $3 \mathrm{~d}$ and Table 1, but the sample values are more scattered. Taking only calcium silicate bricks into account, the positive correlation disappears.

In total, the overall correlation between thermal conductivity and density is smaller than between specific heat and density. We assume that this is caused by material-specific factors with a significant influence on heat conduction, such as grain sizes and interior structure. A theoretic relationship considering these contributions might describe the behaviour better, but its development would be beyond the scope of this work.

\subsubsection{Permittivity to thermal parameters}

The interrelations between permittivity and density and between density and thermal parameters help to draw a connection between permittivity and thermal parameters. As Fig. $3 \mathrm{f}$ and the correlation value of 0.895 show, specific heat values of the investigated materials can be estimated from permittivity values. The advantage of using the left side of the ClausiusMossotti equation to reach a linear relationship is visible when comparing (Figs. 2 and 3f). The scattering of the values is high, but the influence of thermal capacity on building energy demand is limited anyway. Deriving values for thermal conductivity from permittivity is feasible. For a linear fit to the left side of the Clausius-Mossotti equation, we observe a residual standard deviation of $0.259 \mathrm{~W} / \mathrm{mK}$ and a relative residual standard deviation of $30.0 \%$ for the thermal conductivity over all samples. The values decrease to $0.105 \mathrm{~W} / \mathrm{mK}$ and $13.2 \%$ respectively if the existence of calcium silicate bricks and lightweight aggregated concrete with closed structure can be ruled out in advance (see also Fig. 3e). Regarding the latter, it was very hard to classify the samples when talking to practitioners; it seems to be a rarely used material. Furthermore, the two samples were found as parts of interior walls. Regarding the first, calcium silicate bricks are common in exterior walls. Their above mentioned tendency to have higher imaginary parts of relative permittivity may give a hint towards their existence if no other source (like old plans or owner's knowledge) is available.

All in all, the hypothesis of an interrelation between permittivity and thermal parameters is at least partly confirmed. More samples are needed to get a better understanding. Especially, more of the non-BCB stones mentioned here, other materials that appear in external walls, and specimens from other regions would be helpful for an improvement of the database.

\subsection{Measurement accuracy}

The TPS measurements were repeatedly performed by the device to prevent dynamic effects of the surrounding temperature. Furthermore, the samples were repeatedly measured in different seasons. The variation of repeatedly measured values lies mostly well within the uncertainty mentioned in Sect. 3.3. Some exceptions can be traced back to inhomogeneous material or very low thermal conductivity. We did not observe a systematic influence of the season. In conclusion, it seems reasonable that the uncertainty of $\pm 5 \%$ determined by Log and Gustafsson [21] applies here, too.

Table 2 compares our measured values to the standard material parameters available from CIBSE Guide A.

Measured thermal conductivities are smaller than in the guide for all material types but CSB, which is consistent with the guide's statement that "[p]articular masonry products can have thermal conductivities significantly lower than the corresponding values given" [9]. When concerning (Fig. 3c), the CIBSE values for $\mathrm{BCB}$ are at the upper end of the scattered sample values. The same is valid for BCB and CSB 
Table 2 Comparison between material properties tabulated in CIBSE Guide A [9] $(C)$ and linear fit to measured thermal properties $(M)$ for the respective densities

\begin{tabular}{lcccccc}
\hline Material & $\rho\left[\mathrm{kg} / \mathrm{m}^{3}\right]$ & \multicolumn{2}{l}{$k[\mathrm{~W} / \mathrm{mK}]$} & & \multicolumn{2}{c}{$c\left[\mathrm{MJ} / \mathrm{m}^{3} \mathrm{~K}\right]$} \\
& & $M$ & $C$ & & $M$ & $C$ \\
\hline BCB & 1300 & 0.46 & 0.75 & & 1.01 & 1.09 \\
& 1500 & 0.63 & 0.85 & & 1.13 & 1.26 \\
& 1700 & 0.80 & 1.00 & 1.25 & 1.43 \\
CSB & 2000 & 1.61 & 1.50 & 1.34 & 1.68 \\
AAC & 576 & 0.16 & 0.20 & 0.53 & 0.48 \\
LAC open & 720 & 0.17 & 0.26 & 0.61 & 0.60 \\
& 870 & 0.22 & 0.30 & & 0.75 & 0.73 \\
LAC closed & 1760 & 0.44 & 0.66 & & 1.43 & 1.48 \\
\hline
\end{tabular}

CIBSE values for AAC are interpolated to the measured average density

specific heat, while measured specific heat matches the tabulated values very well for AAC and LAC. As the CIBSE values are standard values that (although this is not explicitly stated in the guide) may reflect a worstcase situation, they are consistent with our data. Anyway, repeating the measurements with another measurement device may allow to exclude systematic errors as a reason for the mentioned deviations. As the deviations mostly have the same direction and are similarly large within a material, their possible influence on the correlation between permittivity and thermal parameters is not important for testing our hypothesis.

Regarding permittivity, the two cuboids per sample were measured independently. Repeated measurements of individual cuboids show clearly lower deviation than different cuboids of the same sample stone. The overall standard deviation of repeated measurements to the average value is about $1.5 \%$, which can be considered as uncertainty of the values. Values for comparison are available from the field of communication propagation. An overview is available from an Ofcom project [8]. Specifically, Yahalom et al. [24] and Leschnik and Schlemm [25] list $\varepsilon_{r}^{\prime}$ values of 3.3 to 5.3 for bricks at $5 \mathrm{GHz}$ and $2.45 \mathrm{GHz}$ respectively, which is confirmed by ITU-R Recommendation P.2040-1 [26] giving $\varepsilon_{r}^{\prime}=3.75$ at $1-10$ $\mathrm{GHz}$ and by Abel and Wallace [27]. We discovered only one value $\left(\varepsilon_{r}^{\prime}=3.98\right.$ at $\left.2.45 \mathrm{GHz}\right)$ for calcium silicate bricks in the literature [25]. Regarding lightweight concrete, values between 2 and 3 at $0-5$ $\mathrm{GHz}$ can be found $[28,29]$. For aerated concrete, $\varepsilon_{r}^{\prime}$ values of 2.04 at $2.45 \mathrm{GHz}$ and of 2.26 at presumably $60 \mathrm{GHz}$ were measured [25, 30]. Although all these sources do not specify the density of their samples, we regard our measurements as plausible as they fall within the range of the literature values. In addition, it should be emphasised again that we took great care for realistically dry materials, since high or unknown moisture contents influence the permittivity values considerably.

The uncertainty of density measurements is assumed to be at about $1 \%$, but can hardly be quantified due to the non-digital measurement method. Anyway, density values were only obtained for orientation and are irrelevant for the direct correlation between permittivity and thermal parameters.

\section{Conclusion}

We presented the hypothesis of a correlation between permittivity and thermal parameters for building materials based on the theoretical connection of both material properties to density. To test it, we determined the values of thermal conductivity, thermal capacitance, density, and permittivity for a total of 56 samples of burnt clay bricks, calcium silicate bricks, autoclaved aerated concrete, and lightweight concrete mainly originating from demolished buildings. The initial hypothesis was partly confirmed. In particular, the specific heat of a material can be estimated if the permittivity is known. Furthermore, deriving values for thermal conductivity from permittivity is feasible, especially if the existence of calcium silicate bricks and lightweight aggregated concrete with closed structure can be ruled out in advance. In this case, the standard uncertainty of the thermal conductivity derived from a known permittivity value is expected to be about $13 \%$. This enables us to develop a method for analysing homogeneous wall layers energetically using microwave radar sensing technology. The envisaged approach uses a combination of filtered and unfiltered radar range profiles and SAR imaging for improved azimuth resolution. With the imaging data obtained, a structural analysis of the building wall can be performed that serves as the basis for calculating the individual permittivity of each layer. Using 
the relationships from the presented material investigations, thus the heat transfer coefficients of existing walls can be determined with an approach that is suitable for automation.

Acknowledgements The authors would like to thank Stefan Thurner and Resul Fener (DLR) for assisting in the measurements and the numerous colleagues and externals who helped collecting and/or provided the investigated materials.

Author Contributions Philip Gorzalka: conceptualization, methodology, validation, investigation, resources, formal analysis, writing - original draft. Alexander Haas: conceptualization, methodology, writing-original draft. Galina Golubeva: investigation, validation. Jacob Estevam Schmiedt: conceptualization, funding acquisition, writingreview and editing. Markus Peichl: conceptualization, funding acquisition, writing-review and editing. Bernhard Hoffschmidt: conceptualization, funding acquisition, writing-review and editing.

Funding Open Access funding enabled and organized by Projekt DEAL. This study was funded by the German Ministry for Economic Affairs and Energy in the framework of the "building tomograph" (Gtom) project (Grant No. 03ET1405A).
Conflict of interest The authors have no conflicts of interest to declare that are relevant to the content of this article.

Open Access This article is licensed under a Creative Commons Attribution 4.0 International License, which permits use, sharing, adaptation, distribution and reproduction in any medium or format, as long as you give appropriate credit to the original author(s) and the source, provide a link to the Creative Commons licence, and indicate if changes were made. The images or other third party material in this article are included in the article's Creative Commons licence, unless indicated otherwise in a credit line to the material. If material is not included in the article's Creative Commons licence and your intended use is not permitted by statutory regulation or exceeds the permitted use, you will need to obtain permission directly from the copyright holder. To view a copy of this licence, visit http://creativecommons.org/licenses/by/4.0/.

\section{Appendix}

See Table 3.

\section{Declarations}

Table 3 Average measured material property values for each sample, sorted by material and density

\begin{tabular}{lllllll}
\hline Sample No. & Sample material & $\begin{array}{l}\rho \\
{\left[\mathrm{kg} / \mathrm{m}^{3}\right]}\end{array}$ & $\begin{array}{l}\varepsilon_{r}^{\prime} \\
-\end{array}$ & $\begin{array}{l}\varepsilon_{r}^{\prime \prime} \\
-\end{array}$ & $\begin{array}{l}k \\
{[\mathrm{~W} / \mathrm{mK}]}\end{array}$ & $\begin{array}{l}c \\
{\left[\mathrm{MJ} / \mathrm{m}^{3} \mathrm{~K}\right]}\end{array}$ \\
\hline 1 & BCB red & 1520 & 2.94 & 0.026 & 0.55 & 1.22 \\
2 & BCB red & 1565 & 3.17 & 0.052 & 0.64 & 1.24 \\
3 & BCB red & 1587 & 3.20 & 0.041 & 0.83 & 1.17 \\
4 & BCB red & 1594 & 3.14 & 0.041 & 0.69 & 1.16 \\
5 & BCB red & 1595 & 3.48 & 0.190 & 0.62 & 1.31 \\
6 & BCB red & 1597 & 3.39 & 0.098 & 0.75 & 1.15 \\
7 & BCB red & 1601 & 3.09 & 0.034 & 0.58 & 1.15 \\
8 & BCB red & 1628 & 3.05 & 0.035 & 0.65 & 1.31 \\
9 & BCB red & 1636 & 3.50 & 0.067 & 0.71 & 1.28 \\
10 & BCB red & 1744 & 3.48 & 0.040 & 0.77 & 1.23 \\
11 & BCB red & 1744 & 3.18 & 0.036 & 0.70 & 1.33 \\
12 & BCB red & 1745 & 3.55 & 0.054 & 0.86 & 1.27 \\
13 & BCB red & 1767 & 3.65 & 0.069 & 0.91 & 1.20 \\
14 & BCB red & 1781 & 3.33 & 0.046 & 0.81 & 1.27 \\
15 & BCB red & 1856 & 3.67 & 0.041 & 1.01 & 1.31 \\
16 & BCB red & 1869 & 3.53 & 0.050 & 0.95 & 1.53 \\
17 & BCB red & 1920 & 3.65 & 0.043 & 0.98 & 1.38 \\
18 & BCB red & 1951 & 4.00 & 0.066 & 1.20 & 1.46 \\
19 & BCB red & 1963 & 3.57 & 0.040 & 1.07 & 1.51 \\
20 & BCB red & 1969 & 4.31 & 0.082 & 0.95 & 1.37 \\
\hline & & & & & &
\end{tabular}


Table 3 continued

\begin{tabular}{|c|c|c|c|c|c|c|}
\hline Sample No. & Sample material & $\begin{array}{l}\rho \\
{\left[\mathrm{kg} / \mathrm{m}^{3}\right]}\end{array}$ & $\begin{array}{l}\varepsilon_{r}^{\prime} \\
-\end{array}$ & $\begin{array}{l}\varepsilon_{r}^{\prime \prime} \\
-\end{array}$ & $\begin{array}{l}k \\
{[\mathrm{~W} / \mathrm{mK}]}\end{array}$ & $\begin{array}{l}c \\
{\left[\mathrm{MJ} / \mathrm{m}^{3} \mathrm{~K}\right]}\end{array}$ \\
\hline 21 & BCB red & 1969 & 3.89 & 0.053 & 1.20 & 1.55 \\
\hline 22 & $\mathrm{BCB}$ red & 1980 & 3.74 & 0.048 & 1.10 & 1.45 \\
\hline 23 & BCB red & 1991 & 4.09 & 0.064 & 1.04 & 1.39 \\
\hline 24 & $\mathrm{BCB}$ red & 2001 & 4.08 & 0.058 & 0.90 & 1.47 \\
\hline 25 & $\mathrm{BCB}$ red & 2002 & 4.10 & 0.063 & 1.21 & 1.46 \\
\hline 26 & $\mathrm{BCB}$ red & 2022 & 4.10 & 0.040 & 1.01 & 1.35 \\
\hline 27 & BCB red & 2030 & 3.98 & 0.047 & 1.12 & 1.48 \\
\hline 28 & $\mathrm{BCB}$ red & 2057 & 3.99 & 0.053 & 1.12 & 1.50 \\
\hline 29 & BCB red & 2065 & 4.16 & 0.068 & 1.02 & 1.43 \\
\hline 30 & BCB red & 2073 & 4.22 & 0.079 & 1.01 & 1.49 \\
\hline 31 & $\mathrm{BCB}$ red & 2116 & 4.35 & 0.078 & 1.13 & 1.55 \\
\hline 32 & BCB red & 2162 & 4.24 & 0.064 & 1.12 & 1.55 \\
\hline 33 & BCB yellow & 1440 & 2.95 & 0.046 & 0.60 & 1.06 \\
\hline 34 & BCB yellow & 1702 & 3.68 & 0.110 & 0.79 & 1.25 \\
\hline 35 & BCB yellow & 1759 & 3.74 & 0.072 & 0.86 & 1.09 \\
\hline 36 & BCB yellow & 1845 & 3.93 & 0.042 & 1.05 & 1.26 \\
\hline 37 & BCB scorched & 1374 & 2.89 & 0.036 & 0.61 & 1.10 \\
\hline 38 & BCB scorched & 1483 & 2.72 & 0.045 & 0.68 & 0.98 \\
\hline 39 & BCB scorched & 1783 & 3.65 & 0.062 & 0.97 & 1.34 \\
\hline 40 & BCB scorched & 2103 & 4.72 & 0.176 & 1.12 & 1.38 \\
\hline 41 & CSB & 1856 & 3.82 & 0.144 & 1.27 & 1.41 \\
\hline 42 & CSB & 1871 & 4.12 & 0.177 & 1.38 & 1.49 \\
\hline 43 & CSB & 1903 & 3.75 & 0.123 & 1.37 & 1.35 \\
\hline 44 & CSB & 1974 & 4.70 & 0.257 & 1.52 & 1.65 \\
\hline 45 & CSB & 1981 & 3.73 & 0.082 & 1.59 & 1.53 \\
\hline 46 & CSB & 2006 & 3.80 & 0.097 & 1.64 & 1.09 \\
\hline 47 & CSB & 2034 & 3.99 & 0.113 & 1.69 & 1.21 \\
\hline 48 & AAC & 556 & 1.92 & 0.073 & 0.15 & 0.50 \\
\hline 49 & $\mathrm{AAC}$ & 596 & 2.00 & 0.082 & 0.18 & 0.57 \\
\hline 50 & LAC open & 706 & 2.09 & 0.053 & 0.18 & 0.65 \\
\hline 51 & LAC open & 707 & 2.12 & 0.051 & 0.16 & 0.54 \\
\hline 52 & LAC open & 748 & 2.11 & 0.045 & 0.17 & 0.52 \\
\hline 53 & LAC open & 831 & 2.33 & 0.077 & 0.24 & 0.97 \\
\hline 54 & LAC open & 905 & 2.39 & 0.079 & 0.22 & 0.65 \\
\hline 55 & LAC closed & 1340 & 4.01 & 0.144 & 0.30 & 1.15 \\
\hline 56 & LAC closed & 1810 & 5.43 & 0.187 & 0.46 & 1.47 \\
\hline
\end{tabular}




\section{References}

1. Bürger V, Hesse T, Palzer A, Köhler B, Herkel S, Engelmann P, Quack D (2017) Klimaneutraler Gebäudebestand 2050: Energieeffizienzpotenziale und die Auswirkungen des Klimawandels auf den Gebäudebestand. Umweltbundesamt, Dessau-Roßlau

2. International Organization for Standardization (2014) Standard ISO 9869-1: Thermal insulation: building elements: in-situ measurement of thermal resistance and thermal capacitance: heat flow meter method

3. International Organization for Standardization (2014) Standard ISO 9869-2: Thermal insulation: building elements: in-situ measurement of thermal resistance and thermal capacitance: infrared method for frame structure dwelling

4. Haas A, Peichl M, Dill S (2019) Layer determination of building structures with SAR in near field environment. In: 16th European radar conference (EuRAD), pp 209-212

5. Ivers-Tiffée E, von Münch W (2007) Werkstoffe der Elektrotechnik. Teubner, Wiesbaden. https://doi.org/10. 1007/978-3-8351-9088-7

6. Ulaby FT, Long DG (2015) Microwave radar and radiometric remote sensing. Artech House, Norwood

7. Haas A, Peichl M, Dill S (2017) Theoretical and experimental investigations of microwave signatures for characterization of building structures. In: 2017 18th international radar symposium (IRS), IEEE, Prague, Czech Republic, pp 1-10. https://doi.org/10.23919/IRS.2017.8008089

8. dB Spectrum Services Ltd, Red-M Ltd, Radio Communication Research Unit of CCLRC Rutherford Appleton Laboratory (2007) Ofcom project SES-2005-08: predicting coverage and interference involving the indoor-outdoor interface: final report

9. Anderson B, Doran S, Mina K, Pettit G (2006) Thermal properties of building structures. In: CIBSE (ed) Environmental design: CIBSE guide A, CIBSE, London

10. Johnson JS (1938) Correlation of electrical and thermal properties of building brick. J Am Ceram Soc 21(3):79-85. https://doi.org/10.1111/j.1151-2916.1938.tb15749.x

11. Powell RW (1939) Heat. Rev Sci Inst 6(1):297-329. https:// doi.org/10.1088/0034-4885/6/1/316

12. Perinelli A, Finotti F, Tonelli AM, Ricci L, Albatici R (2019) Experimental apparatus for the determination of thermal conductivity and humidity in building materials by means of electrical permittivity measurements. TEMA Technol Eng Mater Archit 5(2):29-41. https://doi.org/10. 17410/tema.v5i2.226

13. Eifert H (2015) Bauen in Stein: Die Historie der mineralischen Baustoffe in Deutschland und Umgebung. Verlag Bau + Technik, Düsseldorf

14. Metje WR (2007) Keramische und mineralisch gebundene Baustoffe. In: Hiese W (ed) Baustoffkenntnis. Werner Verlag, Neuwied, pp 37-110

15. Knoblauch H, Schneider U (2006) Bauchemie, 6th edn. Werner Verlag, Neuwied

16. Ettel WP (2007) Beton. In: Hiese W (ed) Baustoffkenntnis. Werner Verlag, Neuwied, pp 249-366
17. Pützschler W (2007) Gesteinskörnungen/Zuschläge für Mörtel und Beton. In: Hiese W (ed) Baustoffkenntnis. Werner Verlag, Neuwied, pp 205-248

18. Schumacher B, Bach HG, Spitzer P, Obrzut J (2007) Electrical properties. In: Czichos H, Saito T, Smith L (eds) Springer handbook of materials measurement methods. Springer, Berlin, pp 431-484

19. von Hippel AR (1966) Theory. In: von Hippel AR (ed) Dielectric materials and applications, The M.I.T. Press, Cambridge, MA, pp 3-46

20. Hahn DW, Özisik MN (2012) Heat conduction, 3rd edn. Wiley, Hoboken, NJ

21. Log T, Gustafsson SE (1995) Transient plane source (TPS) technique for measuring thermal transport properties of building materials. Fire Mater 19(1):43-49. https://doi.org/ 10.1002/fam.810190107

22. Nicolson AM, Ross GF (1970) Measurement of the intrinsic properties of materials by time-domain techniques. IEEE Trans Inst Measur 19(4):377-382. https://doi.org/10.1109/ TIM.1970.4313932

23. Ferreira D, Cuinas I, Caldeirinha RF, Fernandes TR (2014) A review on the electromagnetic characterisation of building materials at micro- and millimetre wave frequencies. In: The 8th European conference on antennas and propagation (EuCAP 2014), IEEE, pp 145-149. https://doi.org/10.1109/ EuCAP.2014.6901713

24. Yahalom A, Pinhasi Y, Shifman E, Petnev S (2010) Transmission through single and multiple layers in the 3-10 $\mathrm{GHz}$ band and the implications for communications of frequency varying material dielectric constants. WTOC 9(12):759-772

25. Leschnik W, Schlemm U (1999) Dielektrische Untersuchung mineralischer Baustoffe in Abhängigkeit von Feuchte- und Salzgehalt bei 2,45 GHz. In: Bundesanstalt für Materialforschung und -prüfung, Materialforschungs- und prüfanstalt an der Bauhaus-Universität Weimar, Deutsche Gesellschaft für Zerstörungsfreie Prüfung $\mathrm{eV}$ (eds) Feuchtetag '99, DGZfP-Berichtsband, p P14

26. Radiocommunication Sector of International Communication Union (2015) Recommendation ITU-R P.2040-1. Effects of building materials and structures on radiowave propagation above about $100 \mathrm{MHz}$

27. Abel JR, Wallace JW (2019) 4-40 GHz permittivity measurements of indoor building materials. In: 2019 IEEE international symposium on antennas and propagation and USNC-URSI radio science meeting, IEEE, pp 105-106. https://doi.org/10.1109/APUSNCURSINRSM.2019. 8888911

28. Kubacki R (2014) New attempt to building materials permittivity measurements. In: Progress in Electromagnetics research symposium. The Electromagnetics Academy, Cambridge, PIERS proceedings, pp 2676-2680

29. Radiocommunication Sector of International Communication Union (2009) Recommendation ITU-R P.1238-6. Propagation data and prediction methods for the planning of indoor radiocommunication systems and radio local area networks in the frequency range $900 \mathrm{MHz}-100 \mathrm{GHz}$

30. COST Telecom Secretariat (1999) Digital mobile radio towards future generation systems: COST action 231 final report. European commission, directorate-general 
telecommunications, information society, information market, and exploitation of research, Luxembourg
Publisher's Note Springer Nature remains neutral with regard to jurisdictional claims in published maps and institutional affiliations. 